\title{
Notes on the vocalizations of Blue-naped Chlorophonia (Chlorophonia cyanea)
}

Peter Boesman

In the following we briefly analyze and compare voice of the different races of Blue-naped Chlorophonia (Chlorophonia cyanea). We also try to quantify the extent of any vocal differences using the criteria proposed by Tobias et al. (2010), as a support for taxonomic review. We have made use of sound recordings available on-line from Xeno Canto (XC).

True song reportedly a Euphonia-like medley of different note types (HBW Alive: Hilty et al. 2016), but apparently no recordings available of such vocalization.

A much more commonly-recorded song-like vocalization is a plaintive downslurred whistle repeated at intervals.

Some examples:

nominate:
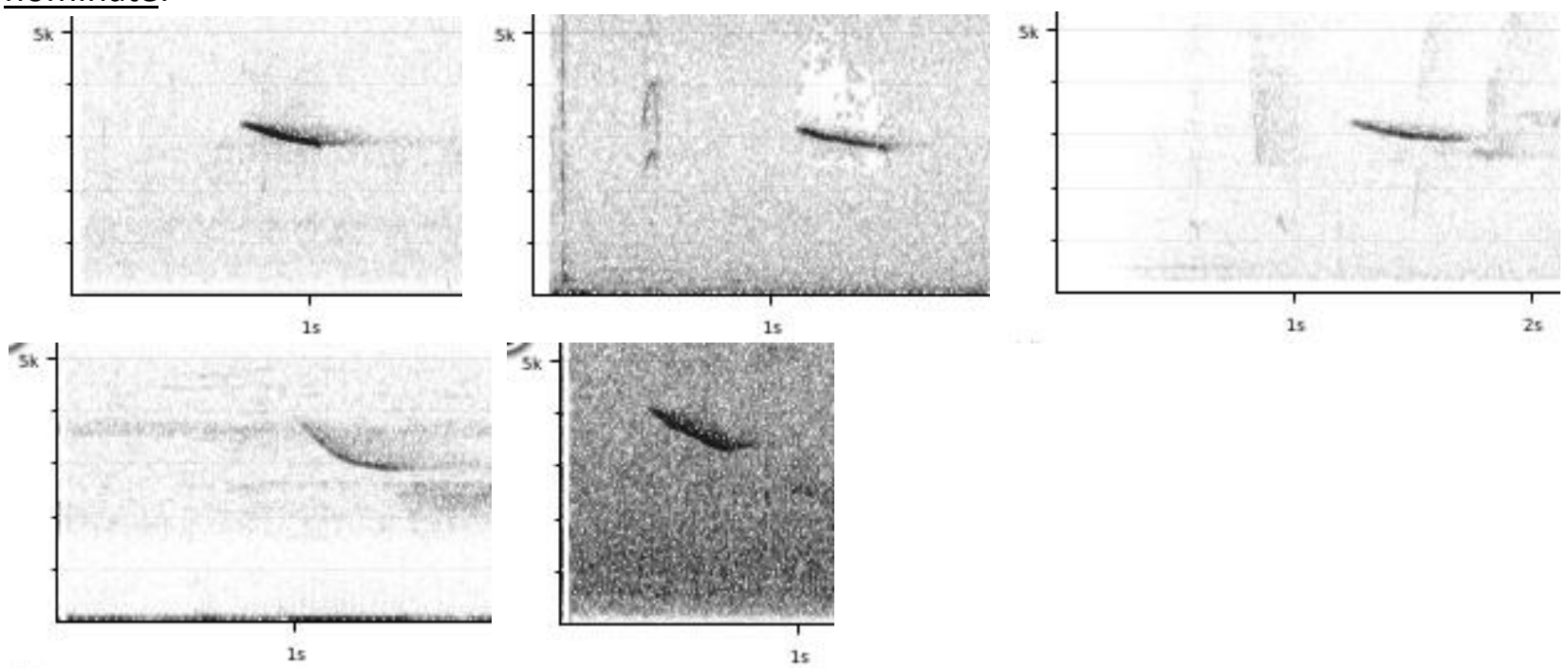

other races:

Colombia (2 first ones from Santa Marta)
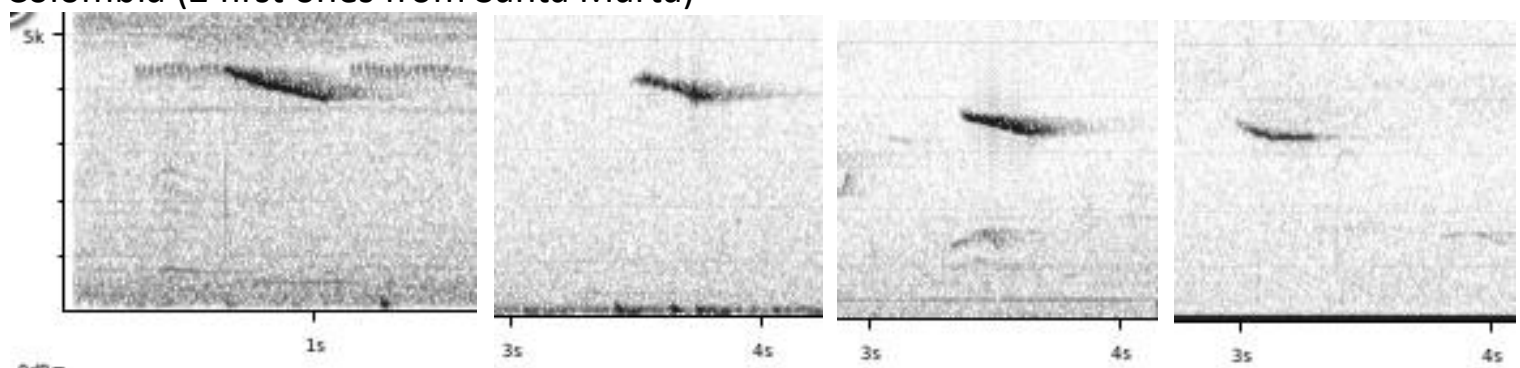

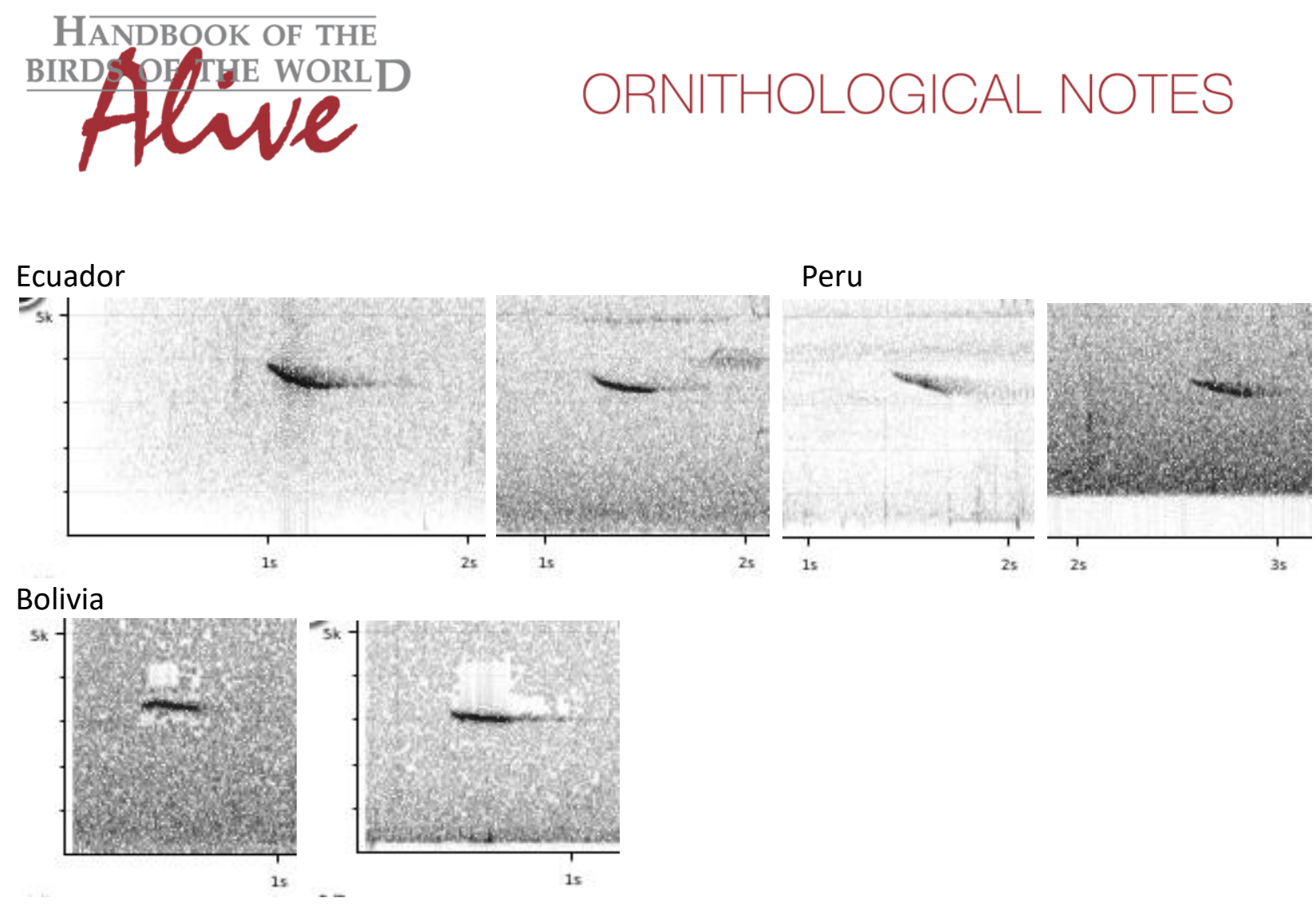

From the above examples, it is clear that this vocalization is very similar among races. Birds from SE Brazil (nominate) seem to reach the lowest pitch at the end of the whistle (around $3 \mathrm{kHz}$ ), birds from Santa Marta the highest (around $4 \mathrm{kHz}$ ), with other races in between. As a matter of fact, it would seem that there is a gradual decrease in pitch from $\mathrm{N}$ to $\mathrm{S}$ along the Andes.

Whistles of nominate apparently on average also slightly longer in duration.

No other clear differences were noted.

All in all, differences based on this single vocalization type rather minor.

This note was finalized on 18th May 2016, using sound recordings available on-line at that moment. We would like to thank in particular the many sound recordists who placed their recordings for this species on XC.

\section{References}

Hilty, S. \& Bonan, A. (2016). Blue-naped Chlorophonia (Chlorophonia cyanea). In: del Hoyo, J., Elliott, A., Sargatal, J., Christie, D.A. \& de Juana, E. (eds.). Handbook of the Birds of the World Alive. Lynx Edicions, Barcelona. (retrieved from http://www.hbw.com/node/61807 on 18 May 2016).

Tobias, J.A., Seddon, N., Spottiswoode, C.N., Pilgrim, J.D., Fishpool, L.D.C. \& Collar, N.J. (2010). Quantitative criteria for species delimitation. Ibis 152(4): 724-746. 


\section{Recommended citation}

Boesman, P. (2016). Notes on the vocalizations of Blue-naped Chlorophonia (Chlorophonia cyanea). HBW Alive Ornithological Note 351. In: Handbook of the Birds of the World Alive. Lynx

Edicions, Barcelona. (retrieved from http://www.hbw.com/node/1252882 on 27 October 2016). 